\title{
PEMERIKSAAN Escherichia Coli MENGGUNAKAN METODE USAP PADA PERALATAN MAKAN DI RUMAH SAKIT UMUM ANDI MAKKASAU KOTA PAREPARE
}

\author{
Examination Escherichia Coli Use Method Wipe on Equipment Eat \\ at Home Sick General Andi Makkasau City Parepare
}

\author{
Andi Suryanti, Rahmi Amir, Makhrajani Majid \\ (Program Studi Kesehatan Masyarakat Fakultas Ilmu Kesehatan Universitas Muhammadiyah \\ Parepare) \\ (andisuriyanti29@gmail.com)
}

\begin{abstract}
ABSTRAK
Rumah Sakit merupakan sarana kesehatan yang menyelenggarakan kegiatan pelayanan kesehatan serta dapat dimanfaatkan untuk pendidikan tenaga kesehatan dan penelitian. Peralatan makan adalah salah satu faktor yang memegang peranan di dalam menularkan penyakit, sebab alat makan yang tidak bersih dan mengandung mikroorganisme dapat menularkan penyakit lewat makanan, sehingga proses pencucian alat makan sangat berarti dalam membuang sisa makanan dari peralatan yang membantu pertumbuhan mikroorganisme dan melepaskan mikroorganisme yang hidup. Penelitian ini bertujuan untuk mengetahui keberadaan Escherechia coli dengan menggunakan metode usap pada alat makan di Rumah Sakit Umum Andi Makkasau Kota Parepare. Jenis penelitian ini menggunakan survey yang bersifat deskriptif dengan analisa laboratorium untuk mengetahui Escherichia coli yang terdapat pada peralatan makan yang digunakan di Rumah Sakit Umum Andi Makkasau Kota Parepare. Sampel dalam penelitian ini sebanyak 4 alat makan (Plato). Data dianalisa secara deskriptif dengan menggunakan tabel manual dan diuraikan dalam bentuk narasi. Hasil penelitian menunjukkan peralatan makan pada Plato A di peroleh jumlah E.coli sebanyak $30 \mathrm{koloni} / \mathrm{cm}^{2}$, Plato B sebanyak $11 \mathrm{koloni} / \mathrm{cm}^{2}$, Plato C sebanyak $70 \mathrm{koloni} / \mathrm{cm}^{2}$, dan Plato D sebanyak $120 \mathrm{koloni} / \mathrm{cm}$. Peralatan makan tersebut positif mengandung Escherichia Coli dan termaksud dalam kategori tidak memenuhi syarat sesuai dengan peraturan yang telah dibuat dalam bentuk Peraturan Menteri Kesehatan RI No.1096/Menkes/SK/VI/2011, bahwa untuk persyaratan higiene sanitasi jasa boga, angka kuman pada peralatan makan 0 (nol).
\end{abstract}

Kata Kunci : Peralatan makan, Escherichia coli

\section{ABSTRACT}

Hospital is a health facility that organizes health service activities and can be used for education of health workers and research. Tableware is one of the factors that play a role in transmitting the disease, because cutlery that is not clean and contains microorganisms can transmit the disease through food, so that the washing process of eating utensils is very meaningful in removing food waste from equipment that helps the growth of microorganisms and releases microorganisms that life. This study aims to determine the existence of Escherechia coli by using the swab method on cutlery at Andi Makkasau General Hospital, Parepare City This type of research uses descriptive surveys with laboratory analysis to find out Escherichia coli contained in eating utensils used in the Andi Makkasau General Hospital in Parepare City. The sample in this study were 4 eating utensils (Plato). Data were analyzed descriptively using manual tables and described in narrative form. The results showed that the tableware in Plato A was 30 colony $/ \mathrm{cm}^{2}$ in E. coli, Plato B in 11 colonies $/ \mathrm{cm}^{2}$, Plato C in 70 colonies / $\mathrm{cm}^{2}$, and 
Plato D in 120 colonies / cm. The tableware is positively containing Escherichia Coli and is meant in the category of not fulfilling the requirements in accordance with the regulations that have been made in the form of the Regulation of the Minister of Health No.1096 / Menkes / SK/ VI / 2011, that for sanitary hygiene requirements catering services, the number of germs on equipment eat 0 (zero).

Keywords: Tableware, Escherichia coli 


\section{PENDAHULUAN}

Peralatan makan adalah salah satu faktor yang memegang peranan di dalam menularkan penyakit, sebab alat makan yang tidak bersih dan mengandung mikroorganisme dapat menularkan penyakit lewat makanan, sehingga proses pencucian alat makan sangat berarti dalam membuang sisa makanan dari peralatan yang membantu pertumbuhan mikroorganisme dan melepaskan mikroorganisme yang hidup. ${ }^{1}$

Di Indonesia peraturan telah dibuat dalam bentuk Peraturan Menteri Kesehatan RI No.1096/Menkes/SK/VI/2011, bahwa untuk persyaratan higiene sanitasi jasa boga, angka kuman pada peralatan makan 0 (nol).

Peranan peralatan makan dalam ruang lingkup Rumah Sakit merupakan bagian yang tak terpisahkan dari usahausaha penyehatan makanan (food hygiene). Peranan peralatan makan dan masak dalam sanitasi makanan sangat penting, untuk itu peranan pembersihan atau pencucian peralatan perlu diketahui secara mendasar. Pembersihan peralatan secara baik akan menghasilkan alat pengolahan makanan yang bersih dan sehat. ${ }^{2}$ Untuk itu pencucian peralatan sangat penting diketahui secara mendasar, dengan pencucian secara baik akan menghasilkan peralatan yang bersih dan sehat pula.

Diketahui hasil penelitian di Instalasi Gizi RSUD Prof. Dr. Margono Soekarjo Purwekerto tahun 2016 menunjukkan bahwa hasil sebelum desinfeksi angka kuman pada alat makan dari 9 sampel ( 3 plato, 3 gelas dan 3 sendok) rata-rata yaitu plato 293.100 koloni/ $\mathrm{cm}^{2}$, gelas 2.933,33 koloni/ $\mathrm{cm}^{2}$ dan sendok 96,333,33 koloni/ $\mathrm{cm}^{2}$. Hasil sesudah desinfeksi angka kuman pada alat makan dari 9 sampel rata-rata yaitu plato 8.733,33 koloni/ $\mathrm{cm}^{2}$, gelas 21,66 koloni $/ \mathrm{cm}^{2}$ dan sendok 1.533,33 koloni $/ \mathrm{cm}^{2}$.

Enam bocah dirawat di Rumah Sakit di Kota Lille, Prancis Utara, karena keracunan makanan yang dikaitkan dengan bakteri E.coli yang tengah mewabah di Eropa. Demikian dilansir, Kamis (16/6/2011). Bocah itu sakit setelah mengkomsumsi daging sapi. Saat ini kondisi 6 pasien cilik itu tidak stabil. Kasus ini menyusul wabah bakteri E.coli yang menewaskan 38 orang, semuanya terjadi di Jerman, kecuali seorang korban wanita yang tewas di Swedia setelah mengunjungi Jerman, dan membuat sakit 3.300 orang di 116 negara.Untuk di Indonesia, bakteri E.coli yang ada diyakini memiliki strainVgalur yang berbeda dengan yang ada di Eropa. Sehingga masyarakat diimbau tetap tenang. ${ }^{4}$

Rumah Sakit merupakan sebuah instansi perawatan kesehatan profesional yang pelayanannya disediakan oleh dokter, perawat, dan tenaga ahli kesehatan lainnya. Selain itu Rumah Sakit juga mempunyai bagian yang khusus menangani masalah 
makanan pasien. Dimana yang menangani masalah diet yang menyangkut penyakit pasien ditangani oleh nutrisionis atau ahli gizi, yang meyediakan atau yang memasak makanan ditangani oleh pramusaji, dan bagi yang mendorong makanan dan cuci piring ditangani oleh pekarya ruangan. Akan tetapi bermacam-macam makanan yang disediakan oleh Rumah Sakit tidak menjadi jaminan kualitas makanan itu baik. Kontaminasi dapat terjadi setiap saat, salah satunya dari peralatan makan yang digunakan tidak memenuhi syarat kesehatan. ${ }^{5}$

Berdasarkan data yang diperoleh dari Rumah Sakit Umum Andi Makkasau Kota Parepare diketahui bahwa petugas yang berada di Rumah Sakit Umum Andi Makkasau Kota Parepare menggunakan air sumur bor dan air PDAM untuk keperluan mencuci peralatan makan dimana penggunaan air sumur bor yang tidak higienis akan rentan terkena pencemaran lingkungan yang berasal dari tanah yang tercemar oleh sampah dan pembuangan kotoran manusia yang berdekatan dengan sumber air, sehingga air tercemar dan mengandung bakteri patogen salah satunya adalah bakteri E. Coli. Keberadaan E.Coli dalam sumber air merupakan indikator pasti terjadinya kontaminasi tinja manusia. Begitupun dengan penggunaan metode Usap diketahui bahwa di Rumah Sakit Umum Andi Makkasau Kota Parepare belum pernah menerapkan metode tersebut. ${ }^{5}$

Berdasarkan observasi di atas maka timbul minat penulis untuk mengkaji lebih dalam mengenai keberadaan bakteri E. Coli pada peralatan makan yang digunakan oleh pihak Rumah Sakit dengan cara melakukan penelitian tentang "Pemeriksaan Escherechia Coli dengan menggunakan metode usap pada alat makan di Rumah Sakit Umum Andi Makkasau Kota Parepare".

\section{BAHAN DAN METODE}

Jenis penelitian ini menggunakan survey yang bersifat deskriptif dengan analisa laboratorium untuk mengetahui Escherichia coli yang terdapat pada peralatan makan yang digunakan di Rumah Sakit Umum Andi Makkasau Kota Parepare. Higiene sanitasi peralatan makan di ukur melalui observasi langsung menggunakan lembar observasi yang berisi 16 pertanyaan dan keberadaan E.coli yang diukur melalui pemeriksaan laboratorium. Pelaksanaan penelitian ini akan dilakukan di Rumah Sakit Umum Andi Makkasau Kota Parepare pada Ruangan Bangsal terkhusus di Ruangan Mawar, Rumah Sakit ini beralamat di Jl. Nurussamawati No.9 Kota Parepare dan pemeriksaan Escherechia Coli dilakukan di Laboratorium Kesehatan Daerah Kota Parepare. Berdasarkan observasi awal yang dilakukan di Rumah Sakit Umum Andi Makkasau Kota Parepare diketahui bahwa jumlah pasien di ruangan Z.Nifas (Bangsal) kelas 111 berjumlah 351 orang dalam 1 bulan terakhir. Jumlah alat makan yang digunakan dalam 1 hari adalah 
10 alat makan (Plato). Sampel dalam penelitian ini yaitu berjumlah 4 alat makan (Plato) dengan perlakuan teknik pengambilan sampel yang digunakan adalah teknik sampel Non Probability Sampels (Purposive Samples), artinya teknik pengambilan sesuai dengan tujuan penelitian.

Data mengenai higiene sanitasi peralatan makan tersebut diperoleh dengan menggunakan lembar observasi. Sedangkan untuk analisis kandungan Escherichia coli data diperoleh dari hasil pengujian di laboratorium berdasarkan hasil uji laboratorium bakteri Escherechia Coli apakah memenuhi syarat atau tidak memenuhi syarat berdasarkan Permenkes RI No.1096/Menkes/SK/VI/2011, bahwa untuk persyaratan higient sanitasi jasa boga, angka kuman pada peralatan makan 0 (nol) dan dianalisa secara deskriptif dengan menggunakan tabel manual dan diuraikan dalam bentuk narasi.

\section{HASIL}

Hasil observasi pada distribusi frekuensi higiene dan sanitasi proses pencucian peralatan makan (Plato) yaitu dapat dikategorikan baik, dimana jumlah frekuensinya sebanyak $11 \quad(68,75 \%)$ sedangkan dikategorikan tidak baik, dimana jumlah frekuensinya sebanyak 5 (31.25\%).

\section{PEMBAHASAN}

Teori Blum dalam Notoatmodjo (2003) pada buku Prinsip-prinsip Dasar
Ilmu Kesehatan Masyarakat, mengatakan bahwa ada 4 faktor yang memengaruhi derajat kesehatan masyarakat yaitu: lingkungan, perilaku, pelayanan kesehatan dan genetik/hereditas. Salah satu faktor yang sangat memengaruhi dari keempat faktor tersebut adalah faktor lingkungan. Faktor lingkungan dinilai memiliki peranan yang besar terhadap kejadian suatu penyakit yang mengakibatkan penurunan derajat kesehatan masyarakat. ${ }^{6}$

Kualitas peralatan makan di Rumah Sakit merupakan salah satu faktor lingkungan yang dapat menyebabkan terjadinya penurunan derajat kesehatan masyarakat khususnya masyarakat yang berada di lingkungan Rumah Sakit. Apabila kualitas dari peralatan makan yang digunakan tersebut tidak memenuhi syarat sesuai dengan Peraturan Menteri Kesehatan yang berlaku maka hal ini akan menyebabkan kejadian penyakit terutama penyakit saluran pencernaan. Selain itu, salah satu faktor yang turut memengaruhi kebersihan peralatan makan yaitu vektor.

Analisis data pada Tabel 1. Menunjukkan bahwa hasil observasi pada distribusi frekuensi higiene dan sanitasi proses pencucian peralatan makan (Plato) yaitu dapat dikategorikan baik, dimana jumlah frekuensinya sebanyak 12 $(68,75 \%)$ sedangkan dikategorikan tidak baik, dimana jumlah frekuensinya sebanyak 5 (31.25\%). 
Berdasarkan hasil observasi atau fakta di lapangan yang dilakukan pada proses pencucian peralatan makan sudah masuk dalam kategori memenuhi syarat atau dalam kategori baik. Dimana para petugas menggunakan air sumur bor dan air PAM untuk melakukan pencucian alat makan.

Hasil penelitian ini sejalan dengan penelitian yang dilakukan Marwah (2006) di Rumah Sakit Umum Lasinrang Kabupaten Pinrang, karena air yang digunakan pada proses pencucian peralatan makan samasama berasal dari PDAM, namun air yang berasal dari sumur bor di RSKD Provinsi Sulawesi Selatan sudah tercemar E. coli yang tidak dapat dipergunakan untuk keperluan dapur di rumah sakit, seperti mencuci peralatan dan masak serta mencuci bahan makanan karena dianggap mengandung mikroorganisme patogen yang berbahaya bagi kesehatan terutama patogen penyebab infeksi saluran pencernaan. ${ }^{7}$

Seperti yang kita ketahui bahwa air sumur bor dampak negatifnya akan terlihat apabila pengambilan air tanah secara intensif juga berisiko pada pencemaran air tanah dalam yang bersumber dari air tanah dangkal. Karena terjadi pencemaran, maka kualitas air tanah yang semula baik akan menurun dan bisa jadi tidak dapat dimanfaatkan ataupun dikonsumsi. Solusinya, sebaiknya air yang dipakai untuk mencuci peralatan makan berasal dari sumber air PDAM agar peralatan makan tidak terkontaminasi oleh E.coli, akan tetapi apabila air dari PDAM tidak cukup untuk memenuhi kebutuhan pencucian di rumah sakit, hendaknya pada sumber air sumur bor dilakukan kaporisasi. Seperti yang kita ketahui bahwa air sumur bor dampak negatifnya akan terlihat apabila pengambilan air tanah secara intensif juga berisiko pada pencemaran air tanah dalam yang bersumber dari air tanah dangkal. Karena terjadi pencemaran, maka kualitas air tanah yang semula baik akan menurun dan bisa jadi tidak dapat dimanfaatkan ataupun dikonsumsi.Kaporisasi yaitu proses membersihkan air yang tercemar bakteri dengan menggunakan bahan kimia yaitu kaporit. Artinya disini, Rumah Sakit lebih memperhatikan penggunaan kaporitnya (takaran).

Ditinjau dari kriteria penggunaan fasilitas dimana pada fakta di lapangan, Rumah Sakit tersebut cukup mempunyai air untuk mencuci peralatan makan, tersedianya bak pembilas yang digunakan petugas untuk membilas peralatan makan (Lihat gambar 14 pada lampiran). Untuk teknik pencucian, Setiap petugas di Rumah Sakit melakukan pembuangan sisa kotoran dan sisa makanan yang terdapat pada peralatan makan yang akan dicuci (Gambar 15 pada lampiran). Hal ini merupakan suatu kebiasaan yang baik dilakukan untuk tahap pencucian peralatan makan. Setelah pembuangan sisa kotoran pada alat makan, dilihat dari proses pencucian peralatan makan petugas melakukannya dengan cara menggosok dan melarutkan sisa makanan menggunakan zat 
pencuci atau detergen tanpa didahului perendaman peralatan makan.

Pekarya juga melakukan proses pencucian alat makan menggunakan detergen yang cukup. Penggunaan detergen yang cukup yaitu dengan detergen cair atau bubuk. Karena detergen sangat larut dalam air sehingga sisa-sisa makanan sedikit kemungkinan membekas pada alat yang dicuci. Petugas Rumah Sakit juga menggunakan air kaporit, tetapi petugas Rumah Sakit tidak mengetahui jumlah kaporit air tersebut.

Dilihat pada hasil observasi petugas juga melakukan pembilasan air di bawah kucuran air kran dan pada saat proses pembilasan terjadi, air kran tersebut tetap dinyalakan. Setelah proses pembilasan, selanjutnya dilakukan proses penirisan. Dimana pada fakta di lapangan yaitu petugas menggunakan penirisan plastik (Gambar 18 pada lampiran). Penirisan peralatan makan yang telah dicuci dilakukan dengan alasan agar air yang masih tertinggal pada peralatan makan, tidak ada pada saat peralatan makan tersebut digunakan kembali

Hasil penelitian pada fakta lapangan di atas sejalan dengan penelitian yang dilakukan oleh Pohan (2009), diperoleh hasil proses pencucian peralatan makan secara keseluruhan sudah memenuhi syarat (Baik) bagi kesehatan sesuai dengan Kepmenkes RI No 715/Menkes /SK/V/2003. ${ }^{8}$
Analisis data pada Tabel 2 menunjukkan bahwa hasil penelitian peralatan makan yang dilakukan di Rumah Sakit Umum Andi Makkasau Kota Parepare yaitu pada plato A jumlah Escherichia Coli sebanyak $30 \mathrm{koloni} / \mathrm{cm}^{2}$, Sedangkan pada penelitian jam 13.09 pada plato B mengandung Escherichia Coli 11 koloni $/ \mathrm{cm}^{2}$. Pada penelitian jam 13.14 pada plato C mengandung Escherichia Coli yaitu sebanyak $70 \mathrm{koloni} / \mathrm{cm}^{2}$. Sedangkan pada penelitian jam 13.16 pada plato D mengandung Escherechia Coli 120 koloni $/ \mathrm{cm}^{2}$. Ke 4 plato tersebut diperoleh adanya Escherichia Coli atau positif mengandung Escherechia Coli dan termaksud dalam kategori tidak memenuhi syarat sebagaimana peraturan RI No.1096/Menkes/SK/VI/2011, bahwa untuk persyaratan higiene sanitasi jasa boga, angka kuman pada peralatan makan 0 (nol).

Penelitian ini sejalan dengan penelitian yang dilakukan oleh Mustafiah Muis (2005) di RSUD Andi Makkasau Parepare, dan hasilnya ditemukan jumlah kuman pada alat makan plato sebanyak 3.624 (pagi), 5.048 (siang), dan 4.261 (malam), untuk alat makan piring lauk diperoleh sebanyak 503 (pagi), 645 (siang), dan 691 (malam), dari hasil diatas dapat disimpulkan bahwa semua peralatan makan di rumah sakit tersebut tidak memenuhi syarat. Hasil penelitian ini juga sejalan dengan penelitian yang dilakukan oleh Marwah (2006) di RSUD Lasinrang Pinrang, dari hasil uji laboratorium usap 
peralatan makan, diketahui tidak ada yang memenuhi syarat berdasarkan Permenkes RI No. 715/Menkes/SK/V/2003 tentang persyaratan hygiene sanitasi jasa boga. ${ }^{9}$

Faktor munculnya Escherechia Coli di sebabkan karna beberapa tahapan yang tidak dilakukan di rumah sakit seperti kegiatan perendaman sebelum mencuci alat makan dan perendaman menggunakan air panas. Dimana setelah peneliti melakukan observasi atau fakta di Lapangan ternyata pada Rumah Sakit tersebut mempunyai alat perendaman (Gambar 16 pada lampiran), tetapi tidak digunakan saat peneliti melakukan penelitian dikarenakan alat tersebut belum dipindahkan ke tempat pencucian piring yang baru. Perlu diketahui juga bahwa Rumah Sakit tersebut sedang melakukan Renovasi. Tahap perendaman merupakan salah satu tahap yang boleh dikatakan penting sebab akan mempermudah proses pengangkatan kotoran yang melekat pada peralatan khususnya kotoran atau sisa-sisa makanan yang tidak mudah terangkat dari permukaan alat.

Menurut Cahyaningsih (2009), perendaman peralatan makan dan bak dibersihkan tiap hari merupakan 2 (dua) hal yang sangat berhubungan dengan kondisi bakteriologis peralatan makan. Perendaman perlu dilakukan karena pada perendaman dimaksudkan untuk memberi kesempatan peresapan air ke dalam sisa makanan yang menempel atau mengeras sehingga menjadi mudah untuk dibersihkan atau terlepas dari permukaan alat (Depkes RI, 2006 dalam
Cahyaningsih, 2009). ${ }^{1}$

Solusinya sebaiknya proses pencucian piring menurut H. Anwar (2007), diawali dengan pembersihan kasar untuk menghilangkan sisa makanan dan membantu pembersihan atau pencucian serta mencegah tersumbatnya saluran tanpa menggunakan air, gunakan tangan, sikat, atau sapu penyerok yang sesuai untuk mengumpulkan dan membuang semua makanan sisa. Kemudian siramlah dengan air dingin untuk mengakhiri pembersihan kasar ini, pembersihan pada bak ini disebut bak pencuci peralatan. Dalam bak ini menggunakan deterjen dengan suhu 65,50 $\mathrm{C}$, penggunaan deterjen dan suhu sebesar itu diharapkan semua sisa makanan dan minuman dapat dirontokkan. Kemudian pembersihan pada bak kedua disebut bak pembilas Dalam bak ini peralatan dibilas dengan air panas $(71,10 \mathrm{C}-76,60 \mathrm{C})$ dan di dalam bak ini diharapkan tidak terjadi kemungkinan masih menempelkan sisa-sisa detergen dan lemak pada alat-alat yang dirinci. Dan pembersihan terakhir pada bak ketiga disebut bak pembilas terakhir atau disinfeksi, di dalam bak ini peralatan untuk terakhir kalinya dibilas dengan air panas dengan sushu $82,2^{\circ} \mathrm{C}$, apabila sulit menyediakan air dengan suhu tersebut maka dapat pula ke dalam bak ini diberi zat persenyawaan Chlor dengan sisa Chlor sebesar $1 \mathrm{mg} /$ liter.

Berdasarkan observasi di Lapangan yaitu pada penyimpanan akhir peralatan makan di rumah sakit disimpan dalam 
keadaan terbuka (Gambar 19 pada lampiran) sehingga dengan mudah debu akan menempel, lalat- lalat atau vektor leluasa hinggap di peralatan makan tersebut, walaupun tempat penyimpanannya ada yang terbuat dari besi namun kebersihannya tidak dijaga. Sehingga keberadaan jumlah kuman pada peralatan makan yang melebihi nilai ambang batas dapat disebabkan karena adanya pencucian peralatan makan yang digunakan pada petugas tersebut tidak sesuai dengan tahapan-tahapan teknik pencucian menurut Depkes (2006). ${ }^{10}$

Hasil penelitian ini sejalan dengan penelitian yang dilakukan oleh Marwah (2006) di RSUD Lasinrang Pinrang, diperoleh hasil observasi tentang tempat penyimpanan peralatan makan, tidak yang memenuhi syarat berdasarkan Permenkes RI No. 715/Menkes/SK/V/2003 tentang persyaratan hygiene sanitasi jasa boga, karena tempat penyimpanan peralatan makannya dalam keadaan terbuka dan berdebu sehingga mudah dijamah oleh vektor dan kuman leluasa berkembangbiak disana. ${ }^{7}$ Solusi yang ingin peneliti tawarkan adalah sebaiknya tempat penyimpanan peralatan makan harus diatur sedemikian rupa sehingga memenuhi syarat dan terlindung dari kontaminasi bakteri atau kuman setelah melalui tahap proses pencucian. Kualitas peralatan makan sangat dipengaruhi oleh tempat penyimpanan peralatan makan tersebut. Oleh karena itu, mutlak diperlukan suatu teknik penyimpanan peralatan makan yang ideal.
Dimana penyimpanannya sebaiknya disesuaikan dengan jenis peralatan makannya masing-masing dalam keadaan tertutup agar peralatan tersebut tetap bersih dan terlindung dari jamahan tikus dan hewan lainnya.

\section{KESIMPULAN DAN SARAN}

Berdasarkan hasil penelitian yang dilakukan di Rumah Sakit Umum Andi Makkasau Kota Parepare mengenai pemeriksaan Escherechia Coli menggunakan metode usap pada peralatan makan, dapat disimpulkan bahwa peralatan makan tersebut positif mengandung Escherichia coli sesuai dengan Peraturan Menteri Kesehatan RI No. 1096/Menkes/SK/VI/2011 tentang persyaratan hygiene sanitasi jasa boga, angka kuman pada peralatan makan 0 (nol). Oleh karena itu di sarankan bagi instansi yang terkait khususnya petugas yang melakukan proses pencucian peralatan makan harus lebih memperhatikan teknik pencucian yang baik dan cara penyimpanan peralatan makan setelah pencucian agar peralatan terhindar dari pencemaran baik pencemaran biologis yang menyebabkan peralatan menjadi tidak memenuhi syarat kesehatan dan Sebaiknya petugas Rumah Sakit melakukan Sanitizing/Desinfection (membebashamakan) dengan cara melakukan rendaman air panas $100^{\circ} \mathrm{C}$ selama 2 menit, menggunakan larutan klor aktif (50 ppm), menggunakan sinar ultraviolet (sinar matahari pagi jam 9 
sampai jam 11) atau peralatan elektrik yang menghasilkan sinar ultraviolet dan menggunakan uap panas (stem) yang

\section{DAFTAR PUSTAKA}

1.Cahyaningsih C.T. Hubungan Higiene Sanitasi Dan Perilaku Penjamah Makanan Dengan Kualitas Bakteriologis Peralatan Makan Di Warung Makan. Yogyakarta: FK UGM; 2009. [Diakses pada tanggal 6 April 2018].

2.Departemen Kesehatan Republik Indonesia. Kumpulan Modul Kursus $H y$ giene Sanitasi Makanan Dan Minuman. Jakarta: Dirjen PPM \& PL; 2004. 3.Saraswati E. Karya Tulis Ilmiah
Komparasi Angka Pada Alat Makan
Sebelum dan Sesudah Desinfeksi Di
Instalasi Gizi RSUD Prof. Margono
Soekarjo Purwekerto.
Kemenkes Semarang; 2016.

4.DetikNews. [serial online]; 2011. [Diakses pada tanggal 9 Mei 2018]. https://news.detik.com/internasional/d1661725/6-bocah-dirawat-di-rs-prancisakibat-ecoli

5.RSUD Andi Makkasau . Profil Rumah Sakit Umum Daerah Andi Makkasau Kota Parepare Tahun 2016. Parepare: Rumah Sakit Umum Daerah Andi Makkasau Kota Parepare; 2016.

6. Notoatmodjo. Prinsip - Prinsip Dasar Ilmu Kesehatan Masyarakat. Jakarta: Rineka Cipta; 2003. biasanya terdapat pada mesin cuci piring (dishwashing machine)

7. Marwah. Studi Kualitas Bakteriologis Peralatan Makan RSU Lasinrang Pinrang, Skripsi sarjana tak diterbitkan: FKM Universitas HasanuddinMakassar; 2006.

8.Pohan, Desmalima. "Pemeriksaan Escherichia Coli pada Usapan Peralatan Makan yang Digunakan oleh Pedagang Makanan di Pasar Petisah Medan Tahun 2009." Skripsi Sarjana [on line], Fakultas Kesehatan Masyarakat Universitas Sumatera Utara, Sumatera Utara; 2009.

9. Muis, M. Studi Tentang Pencucian dan Kondisi Bakteriologis Peralatan Makan di RSU. A. Makkasau Pare-Pare. Skripsi sarjana tak diterbitkan, Kesehatan Lingkungan,Politeknik Kesehatan, Makassar; 2005.

10. Departemen Kesehatan Republik Indonesia. Kumpulan Modul Kursus Hygiene Sanitasi Makanan dan Minuman. Jakarta; 2006.

11. Usman, Lilis Suriani. Pengembangan Sistem Edukasi Pencegahan Penyakit Diare Berbasis Development of Civil Society di Kota Pare-Pare. VISIKES "Jurnal Kesehatan Masyarakat" 2016; 15(2): 79-89. 


\section{LAMPIRAN}

Tabel 1. Distribusi Frekuensi Higiene dan Sanitasi Proses Pencuciaan peralatan Makan (Plato) di Rumah Sakit Umum Andi Makkasau Kota Parepare

\begin{tabular}{lcc}
\hline Kriteria & Frekuensi (f) & Persen (\%) \\
\hline Baik & 11 & 68,75 \\
Tidak baik & 5 & 31,25 \\
\hline Total & 16 & 100 \\
\hline
\end{tabular}

Sumber : Data Primer (2018)

Tabel 2. Hasil Pemeriksaan Laboratorium Escherichia Coli pada Peralatan Makan (Plato) di Rumah Sakit Umum Andi Makkasau Kota Parepare

\begin{tabular}{ccccc}
\hline Waktu & $\begin{array}{c}\text { Alat } \\
\text { Makan }\end{array}$ & $\begin{array}{c}\text { Jumlah } \\
\text { Escherichia } \\
\text { Coli }\end{array}$ & $\begin{array}{c}\text { Escherichia } \\
\text { Coli }\end{array}$ & Keterangan \\
\hline $28 / 6 / 2018$ & Plato A & $30 \mathrm{koloni} / \mathrm{cm}^{2}$ & Positif & Tidak \\
13.07 & & & $\begin{array}{c}\text { Memenuhi } \\
\text { Syarat }\end{array}$ \\
WITA & & & Positif & Tidak \\
$28 / 6 / 2018$ & Plato B & $11 \mathrm{koloni} / \mathrm{cm}^{2}$ & & $\begin{array}{c}\text { Memenuhi } \\
\text { Syarat }\end{array}$ \\
WITA & & & Positif & Tidak \\
$29 / 6 / 2018$ & Plato C & $70 \mathrm{koloni} / \mathrm{cm}^{2}$ & & $\begin{array}{c}\text { Memenuhi } \\
\text { Syarat }\end{array}$ \\
WITA & & & Positif & Tidak \\
$29 / 6 / 2018$ & Plato D & $120 \mathrm{koloni} / \mathrm{cm}^{2}$ & & Memenuhi \\
13.16 & & & & Syarat \\
WITA & & & & \\
\hline
\end{tabular}

Sumber : Data Primer (2018)

Tabel 2. menunjukkan bahwa hasil pemeriksaan laboratorium sampel pada peralatan makan (plato) Dimana pada penelitian jam 13.07 pada plato A mengandung Escherechia Coli yaitu sebanyak $30 \mathrm{koloni} / \mathrm{cm}^{2}$. Sedangkan pada penelitian jam 13.09 pada plato B mengandung Escherichia Coli $11 \mathrm{koloni} / \mathrm{cm}^{2}$. Pada penelitian jam 13.14 pada plato C mengandung Escherichia Coli yaitu sebanyak 70 koloni/ $/ \mathrm{cm}^{2}$. Sedangkan pada penelitian jam 13.16 pada plato D mengandung Escherechia Coli $120 \mathrm{koloni} / \mathrm{cm}^{2}$. Ke 4 plato tersebut diperoleh adanya Escherichia Coli atau positif mengandung Escherechia Coli dan termaksud dalam kategori tidak memenuhi syarat sebagaimana peraturan RI No.1096/Menkes/SK/VI/2011, bahwa untuk persyaratan higiene sanitasi jasa boga, angka kuman pada peralatan makan 0 (nol). 